
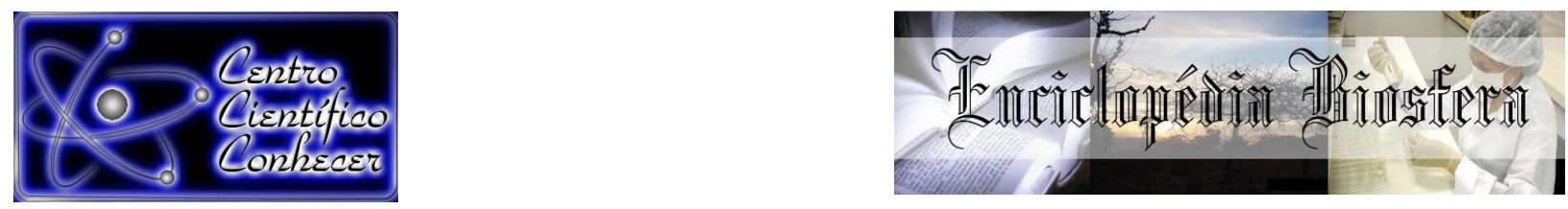

\title{
ENRAIZAMENTO DE HORTELÃ-VERDE (Mentha spicata) EM DIFERENTES TEMPOS DE EXPOSIÇÃO EM ÁCIDO INDOLBUTÍRICO
}

\author{
*Yweenns Teixeira Ferraz", Francisco Fabio Albuquerque Mota ${ }^{2}$, José Darlon \\ Nascimento Alves ${ }^{3}$, Lucila Elizabeth Fragoso Monfort ${ }^{4}$, Ricardo Shigueru Okumura ${ }^{5}$ \\ ${ }^{1}$ Discente da Universidade Federal Rural da Amazônia, Capitão Poço - Brasil. Email: \\ ivens.ferraz@hotmail.com, \\ ²Engenheiro agrônomo, \\ ${ }^{3}$ Engenheiro agrônomo e doutorando em Engenharia Agrícola pela Universidade \\ Federal de Viçosa, \\ ${ }^{4}$ Professora Dr. Adjunto da Universidade Federal Rural da Amazônia, \\ ${ }^{5}$ Professor Dr. Adjunto Da Universidade Federal Rural da Amazônia
}

Recebido em: 06/04/2018 - Aprovado em: 10/06/2018 - Publicado em: 20/06/2018 DOI: 10.18677/EnciBio_2018A42

\begin{abstract}
RESUMO
Objetivou-se avaliar diferentes tempos de imersão em ácido indolbutírico (AIB) no enraizamento de estacas de hortelã verde. O experimento foi conduzido no período de maio a junho de 2014, na Universidade Federal Rural da Amazônia - Campus Capitão Poço (PA). O delineamento experimental foi o inteiramente casualizado, com os seguintes tratamentos: 0,10 e 20 minutos de imersão das estacas na solução de 500 ppm de ácido indolbutírico, denominados de testemunha, recomendado e superior, respectivamente, com quatro repetições, contendo cinco estacas por parcela. Os dados foram submetidos à análise de variância com aplicação do teste $\mathrm{F}$ e as médias comparadas entre si pelo teste de Tukey, a $5 \%$ de probabilidade. Os tratamentos diferiram estatisticamente, ficando evidente que para uma maior sobrevivência das estacas, a exposição pelo tempo superior ao recomendado foi o que promoveu melhor resultado. O número de raízes enraizadas apresentou melhor resultado estatisticamente na exposição do tratamento superior, ou seja, quanto maior o tempo das raízes expostas à solução melhor e/ou maior número de raízes. A imersão das estacas de hortelã verde (Mentha spicata) na solução, em termos gerais teve um maior desempenho das variáveis no tratamento com tempo de 20 minutos.
\end{abstract}

PALAVRAS-CHAVE: auxina, propagação vegetativa, regulador de crescimento.

\section{GREEN MINT ROOTING (Mentha spicata) IN DIFFERENT TIMES OF EXPOSURE IN INDOLBUTYRIC ACID}

\begin{abstract}
The objective was to evaluate different immersion times in indolebutyric acid (AIB) in the rooting of green peppermints. The experiment was conducted in the period from May to June 2014 at the Federal Rural University of Amazonia - Capitão Poço Campus (PA). The experimental design was a completely randomized design, with the following treatments: 0,10 and 20 minutes of immersion of the cuttings in the
\end{abstract} ENCICLOPÉDIA BIOSFERA, Centro Científico Conhecer - Goiânia, v.15 n.27; p. 1982018 
solution of $500 \mathrm{ppm}$ of indolebutyric acid, referred to as control, recommended and superior, respectively, with 4 replicates, containing 5 stakes per portion. The data were submitted to analysis of variance with application of the $F$ test and the means compared to each other by the Tukey test, at $5 \%$ probability. The treatments differed statistically, being evident that for a greater survival of the cuttings, the exposure for the time superior to the recommended one was the one that promoted better result. The number of rooted roots presented a better result statistically in the upper treatment exposition, ie, the longer the roots exposed to the better solution and / or the greater number of roots. The immersion of the green peppermints (Mentha spicata) in the solution, in general terms had a higher performance of the variables in the treatment with time of 20 minutes.

KEYWORDS: auxin, growth regulator, vegetative propagation.

\section{INTRODUÇÃO}

A família Lamiaceae contém vários membros com uma quantidade significativa de óleos essenciais (RAUT; KARUPPAYIL, 2014). Pertencente a esta família, o gênero Mentha, abrange aproximadamente de 25 a 30 espécies, que podem ser localizadas em regiões temperadas da Europa, Ásia, Austrália e África do Sul (SANTOS et al., 2012).

A Mentha spicata L é originária da Europa, especificamente Europa Central, cultivada nos Estados Unidos e Canadá. É uma das espécies de hortelã mais cultivadas no Brasil, pois é bem adaptada ao clima subtropical (CHOUDHURY et al., 2006; FEITOSA et al., 2014). As espécies mais cultivadas no Brasil são a Mentha Avernsis e a Mentha spicata, pois, ambas são bem adaptadas ao clima subtropical, com o clima oscilando entre $18^{\circ}$ e $24^{\circ} \mathrm{C}$, apesar de suportarem temperaturas de até $40^{\circ} \mathrm{C}$ na máxima e $5^{\circ} \mathrm{C}$ na mínima (FEITOSA et al., 2014).

A hortelã (Mentha spicata) é uma planta medicinal utilizada no mundo principalmente para fitoterapia. Tarfurt-Garcia et al. (2014) caracterizam os óleos essenciais das folhas e das inflorescências, apresentando cânfora e acetato de bornila, respectivamente, como seus componentes majoritários, ainda ocorrendo Ecariofileno em ambos. Visando um aumento de propagação e/ ou cultivo desta espécie, o método de estaquia possibilita a obtenção de várias plantas idênticas a partir de uma única planta matriz (GRANDI, 2014). Além disso, vários fatores podem influenciar o enraizamento das estacas, tanto intrínsecos, relacionados à própria planta, quanto extrínsecos, ligados às condições ambientais; mesmo assim, a dificuldade no enraizamento de estacas de algumas espécies pode ser superada se fornecidas as condições ótimas para o enraizamento (HERNANDEZ et al., 2013; MARIOSA, 2014).

Outro fator que também exerce influência no enraizamento é o potencial genético que cada cultivar pode apresentar (ROSA et al., 2017). Fatores como potencial genético do cultivar, balanço hormonal endógeno e consistência dos tecidos das estacas (maior ou menor espessura do anel de esclerênquima) são primordiais para o desenvolvimento das raízes.

Os reguladores vegetais são definidos como produtos químicos sintéticos com atividades fisiológicas nas plantas, a ação desses fitoreguladores está ligada diretamente a alterações fisiológicas e morfológicas das plantas relacionadas 
diretamente ao crescimento e desenvolvimento controlando principalmente atividades meristemáticas e reprodutivas dos vegetais (TAIZ; ZEIGLER, 2013).

O grupo de reguladores de crescimento utilizado com maior frequência é o das auxinas, que são essenciais no processo de enraizamento, por serem reguladores centrais na indução, crescimento e desenvolvimento das raízes (SAINI et al., 2013), e com isso, melhoria do sistema radicular. Diante disso, o regulador ácido indolbutírico pertencente ao grupo das auxinas é o principal responsável pela divisão, alongamento celular e formação de raízes adventícias em estacas, sendo que a emissão de raízes laterais e adventícias é estimulada pelos altos níveis de auxina ou pelo tempo de imersão (VERNIER; CARDOSO, 2013). É utilizado na formulação de diversos compostos visando ao enraizamento de estacas (PETRI et al., 2016).

Há poucos estudos sobre fatores que influenciam nesse processo de enraizamento da hortelã. Portanto, torna-se necessário o conhecimento de novos métodos que auxiliem na produção de raízes adventícias com a finalidade de otimizar os métodos de propagação que possam permitir a manutenção das características genéticas que se espera, permitindo o aumento no desenvolvimento de raízes adventícias em estacas de hortelã. O objetivo deste trabalho foi avaliar diferentes tempos de imersão em ácido indolbutírico no enraizamento de estacas de hortelã verde.

\section{MATERIAL E MÉTODOS}

O experimento foi conduzido no período de maio a junho de 2014, no município de Capitão Poço (Figura 1) dentro da Universidade Federal Rural da Amazônia - Campus Capitão Poço (PA), em casa de vegetação. 


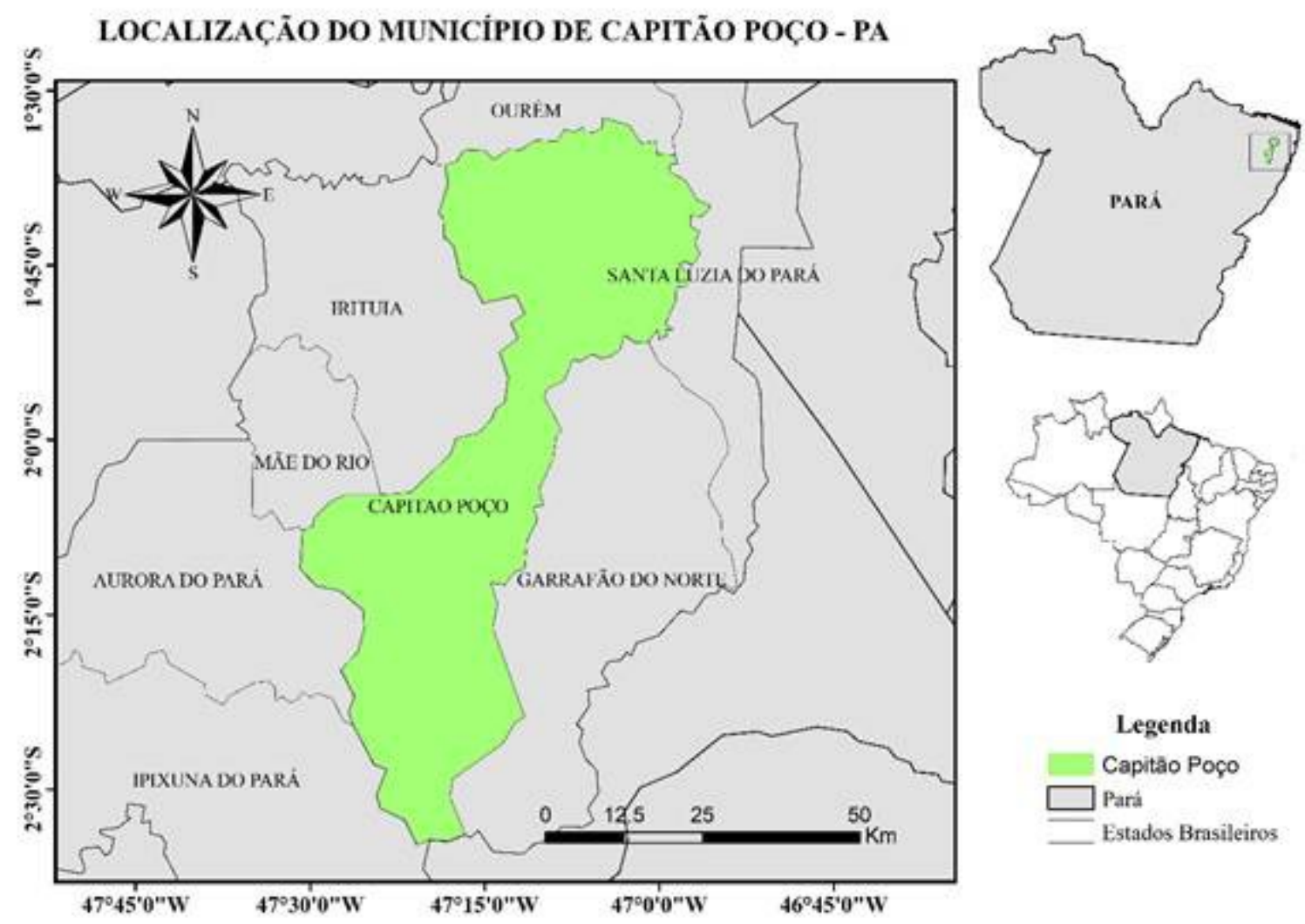

FIGURA 1. Localização do município de Capitão Poço - PA.

Fonte: dados da pesquisa

Foram utilizadas estacas da hortelã verde (Mentha spicata), de aproximadamente $7-9 \mathrm{~cm}$ de comprimento. $O$ delineamento experimental adotado foi o inteiramente casualizado, com os seguintes tratamentos: testemunha, recomendado e superior, onde foi indicado por 0,10 e 20 minutos de imersão das estacas na solução, respectivamente, com quatro repetições, contendo cinco estacas por parcela, o que totalizou 60 estacas.

Antes de efetuar a coleta das estacas foi preparada a solução do ácido indolbutírico (AIB), pesando-se $0,5 \mathrm{~g}$ de $\mathrm{AlB}$ e $20 \mathrm{~g}$ de $\mathrm{NaOH}$ em balança semianalítica, e dissolvendo-se em $50 \mathrm{~mL}$ de água destilada em Becker com auxílio de um agitador de vidro. Após, totalmente dissolvido o AIB, completou-se o volume para $1000 \mathrm{~mL}$ com água destilada, obtendo-se então a concentração de 500 ppm de AIB (MAIA; CAMARGO, 2005).

O preparo das estacas consistiu de um corte de forma horizontal logo abaixo de três nós do meristema apical. Durante o preparo das estacas, estas foram colocadas em recipientes com água para evitar a desidratação. Após o preparo, a porção basal das estacas, em torno de $4 \mathrm{~cm}$ da base da estaca, foram imersas na solução de AIB a 500 ppm nos diferentes tempos 0,10 e 20 minutos e imediatamente colocadas para enraizamento em bandejas de 128 células, contendo areia autoclavada, em mini estufa com cobertura de filme de polietileno transparente, durante o período de 30 dias, sendo que as plantas foram irrigadas diariamente com borrifador manual.

As avaliações foram realizadas após 30 dias de instalação do experimento, nas quais foram mensuradas as seguintes variáveis: sobrevivência das estacas (\% de estacas vivas); brotação (\% de estacas que emitiram brotos) na qual foi realizado ENCICLOPÉDIA BIOSFERA, Centro Científico Conhecer - Goiânia, v.15 n.27; p. 2012018 
por meio de visualização para as duas primeiras e anotados os resultados, respectivamente; estacas enraizadas (\% que emitiram pelo menos uma raiz); número de raízes por estaca (consideradas apenas aquelas que se originaram diretamente da estaca) por meio de contagem manual da quantidade total, respectivamente; e comprimento de raízes por estaca $(\mathrm{cm})$, mensurado por meio de uma régua de $30 \mathrm{~cm}$ (AQUINO et al., 2017).

Inicialmente, nos dados experimentais obtidos foi avaliada a normalidade dos dados e homogeneidade das variâncias, sem a necessidade de transformação dos dados. Uma vez atendidos os pressupostos básicos, os dados foram submetidos à análise de variância com aplicação do teste $\mathrm{F}$ e as médias comparadas entre si pelo teste de Tukey, a $5 \%$ de probabilidade, utilizando o programa estatístico SISVAR (FERREIRA, 2014).

\section{RESULTADOS E DISCUSSÃO}

De acordo com os dados analisados, os tratamentos diferiram estatisticamente $(p<0,05)$, ficando evidente que para uma maior sobrevivência (SOBREV) das estacas, cerca de $95 \%$, a exposição pelo tempo superior ao recomendado foi o que promoveu melhor resultado (Tabela 1). No trabalho de Oliveira et al. (2015), durante a fase de enraizamento, houve aproximadamente 95\% de sobrevivência das miniestacas em todos os tratamentos. A propagação vegetativa por meio do uso de estacas é a técnica de multiplicação de plantas com maior viabilidade econômica para o estabelecimento de plantio comercial, pois permite com menor custo, a multiplicação de genótipos de interesses (MENDES et al., 2014). Algumas espécies apresentam limitações na obtenção de mudas por propagação vegetativa, principalmente devido à dificuldade de enraizamento das estacas. Para as espécies de difícil enraizamento, o uso dos reguladores vegetais tem sido uma forma de aumentar ou proporcionar o enraizamento (FELICIANA et al., 2017).

TABELA 1. Resultados da porcentagem de sobrevivência (SOBREV), brotação (B) e estacas enraizadas (EE), número de raízes (NR) e comprimento de raízes por estaca (CRE).

\begin{tabular}{lrrrrr}
\hline Exposição (tempo) & SOBREV (\%) & B (\%) & EE (\%) & NR & CRE (cm) \\
\hline Testemunha & $35,00 c^{*}$ & $20,00 \mathrm{a}$ & $85,00 \mathrm{a}$ & $2,20 \mathrm{~b}$ & $1,08 \mathrm{~b}$ \\
Recomendado & $60,00 \mathrm{~b}$ & $35,00 \mathrm{a}$ & $50,00 \mathrm{~b}$ & $1,60 \mathrm{~b}$ & $1,11 \mathrm{~b}$ \\
Superior & $95,00 \mathrm{a}$ & $40,00 \mathrm{a}$ & $100,00 \mathrm{a}$ & $4,95 \mathrm{a}$ & $1,99 \mathrm{a}$ \\
\hline Média geral & 63,33 & 31,67 & 78,33 & 2,92 & 1,39 \\
\hline
\end{tabular}

"Médias seguidas por letras iguais na coluna não apresentam diferença estatística com base no teste de Tukey a $5 \%$ de significância.

De acordo com Botelho et al. (2005), dependendo do tempo de exposição, a auxina inibe ou estimula o crescimento e a diferenciação dos tecidos, existindo um nível ótimo para estas respostas fisiológicas em cada espécie. Para Taiz e Zeiger (2013), a inibição, além da concentração ótima, é em geral atribuída a biossíntese de etileno induzida por auxina. Presume-se então que com o aumento do tempo de imersão da base dos explantes, obtém-se resultados mais promissores, pois comparando com outros trabalhos, os tempos superiores apresentaram melhores resultados (SANTOS et al., 2011).

Com relação à brotação $(B)$ das raízes, os dados não apresentaram diferença significativa, o que evidencia que mesmo com diferentes tempos de exposições de AIB as estacas não apresentaram maior porcentagem de brotação de raízes (Tabela 
1). Isto se deve ao enraizamento das estacas (EE), e consequentemente, a brotação das mesmas, serem influenciadas por vários fatores, tanto os intrínsecos (vias metabólicas, respiração entre outros), relacionados à própria planta, como os extrínsecos (clima, solo, luminosidade), relacionados às condições ambientais, interferindo assim, no vingamento das plantas (NORBERTO et al., 2001).

Para a variável estacas enraizadas (EE) foi observada superioridade na exposição de tempo dos tratamentos testemunha e superior comparativamente ao recomendado (Tabela 1). Vale salientar que quanto mais estacas enraizadas, maior a superfície de contato das raízes com o solo e melhor absorção de água e nutrientes, possibilitando melhores subsídios para desenvolvimento da planta.

A utilização de fitoreguladores tem a característica de proporcionar também melhor balanço hormonal nas estacas, e diminui o tempo necessário para inicio de enraizamento (OLIVEIRA et al., 2003). Bentanin e Nienow (2010) observaram em trabalho envolvendo enraizamento de estacas de corticeira-da-serra (Erythrina falcata Benth.) utilizando AIB com tratamentos nas doses de 0, 1000, 2000 e 3000 $\mathrm{mg} \mathrm{L}^{-1}$ que estimularam o enraizamento das estacas foliares em $35,4 \%$. Tiberti et al. (2015), também concluíram em seu trabalho que estacas caulinares registraram $76,5 \%$, os melhores índices de enraizamento com o uso de regulador AIB, se tornando o mesmo indispensável.

O número de raízes (NR) apresentou melhor resultado estatisticamente na exposição do tratamento superior, ou seja, quanto maior o tempo das estacas expostas à solução melhor e/ou maior número de raízes (Tabela 1). Confirmando o observado por Engel et al. (2017), de que o regulador AIB interfere na quantidade de raízes produzidas, neste caso aumentando através do melhor tratamento. Além do mais, o AIB estimula as estacas a sintetizarem raízes maiores, fortes e fibrosas (HARTMANN; KESTER, 2002). No trabalho de Souza e Corrêa (2008), o tempo de imersão influenciou nos resultados desta característica, verificando que o maior tempo de imersão em minutos na concentração de $500 \mathrm{mg} \mathrm{L}^{-1}$ de AIB seria o mais adequado para favorecerem maior porcentagem de enraizamento em estacas de figueira.

Tosta et al. (2012), observaram aumento no comprimento das raízes, com a utilização de AIB. No presente trabalho observou-se que para o comprimento de raízes por estaca (CRE) nos tratamentos testemunha e a recomendada não obtiveram diferença significativa, por sua vez, o tratamento exposição superior diferiu em relação aos outros dois tratamentos, no qual foi possível verificar melhor resultado para comprimento de raízes por estaca (Tabela 1). Souza e Corrêa (2008), estudando diferentes tempos de imersão em solução nutritiva para enraizamento, verificaram que o tempo de oito minutos promoveu os melhores resultados para o comprimento de raízes. Tosta et al. (2012), observaram aumento no comprimento das raízes, com a utilização de AIB.

\section{CONCLUSÃO}

A imersão das estacas de hortelã verde (Mentha spicata) na solução de 500 ppm de ácido indolbutírico (AIB), em termos gerais teve um maior desempenho das variáveis no tratamento com tempo superior (20 minutos).

\section{REFERÊNCIAS}


AQUINO, L. P.; SCHMIDT, R.; DUBBERSTEIN, D.; DIAS, J. R. M. Cortes basais e substratos na formação de mudas clonais de cafeeiro canéfora. Coffee Science, Lavras, v. 12, $\quad$ n. 1 , p. 9 - 16. 2017. Disponível em <http://www.sbicafe.ufv.br:80/handle/123456789/8256>.

BENTANIN, L.; NIENOW, A. A. Propagação vegetativa da corticeira-da-serra (Erythrina falcata Benth.) por estaquia caulinar e foliar. Semina: Ciências Agrária, Londrina, v. 31, n. 4, p. 871-880, 2010. Disponível em: <http://dx.doi.org/10.5433/1679-0359.2010v31n4p871>. doi: 10.5433/16790359.2010v31n4p871

BOTELHO, R. V.; MAIA, A. J.; PIRES, E. J. P.; TERRA, M. M.; SCHUCK, E. Efeitos de reguladores vegetais na propagação vegetativa do porta-enxerto de videira "4343" (Vitis vinífera x Vitis rotundifolia). Revista Brasileira Fruticultura, v. 27, n. 1, p. 6-8, 2005. Disponível em: <http://www.scielo.br/pdf/rbf/v27n1/24553.pdf>.

CHOUDHURY, R. P; KUMAR, A; GARG, A. N. Analysis of Indian mint (Mentha spicata) for essential, trace and toxic elements and its antioxidant behaviour. In press. Journal of Pharmaceutical and Biomedical Analysis. v.7; n.3, p.25-32, 2006. Disponível em: <http://dx.doi.org/10.1016/j.jpba.2006.01.048>. doi:10.1016/j.jpba.2006.01.048

ENGEL, M. L.; HIGA, A. R.; ALCANTARA, G. B.; FLÔRES JUNIOR, P. C.; SOARES, I. D. Enraizamento de miniestacas de diferentes clones de Acacia mearnsii De Wildeman com aplicação de AIB. Revista Espacios, v. 38, n. 23, p. 8-19, 2017. Disponível em: <http://www.revistaespacios.com/a17v38n23/a17v38n23p08.pdf>.

FEITOSA, R. M. DANTAS, R. L. GOMES, W. C. MARTINS, A. N. A. ROCHA, A. P. T. Influência do método de extração no teor de óleo essencial de hortelã (Mentha spicata). Revista Verde, v. 9, n. 4, p. 238 - 241, 2014. Disponível em: <http://oaji.net/articles/2015/2238-1445890950.pdf>.

FELICIANA, A. M. C. MORAIS, E. G. REIS, É, S. CORRÊA, R. M. GONTIJO, A. S. VAZ, G. H. B. Influência de auxinas e tamanho de estacas no enraizamento de azaleia (Rhododendron simsii Planch.). Global Science and Technology. v.10, n. 1, p. $43 \quad-\quad 50, \quad 2017 . \quad$ Disponível em: <https://rv.ifgoiano.edu.br/periodicos/index.php/gst/article/view/850>. 
FERREIRA, D. F. Sisvar: a Guide for its Bootstrap procedures in multiple comparisons. Ciência e Agrotecnologia, Lavras, v. 38, n.2, p. 109-112, 2014. Disponível em: <http://dx.doi.org/10.1590/S1413-70542014000200001>. doi: 10.1590/S1413-70542014000200001

GRANDI, T. S. M. Tratado das Plantas Medicinais: mineiras, nativas e cultivadas. Belo Horizonte: Adequatio Estúdio. 2014. 1204p. Disponível em: < https://plantasmedicinaismineiras.wordpress.com/>.

HARTMANN, H. T.; KESTER, D. E. Plant propagation: principles and practices. 7. Ed. New Jersey: Prentice-Hall, 2002, 880 p.

HERNANDEZ, W. XAVIER, A. PAIVA, H. N. WENDLING, I. Propagação vegetativa do jequitibá - rosa (Cariniana estrellensis (Raddi) KUNTZE). Por estaquia. Revista Árvore, Viçosa, v. 37, n. 5, p. 955-967, 2013. Disponível em: $<$ http://ainfo.cnptia.embrapa.br/digital/bitstream/item/99855/1/2013-API-

PropagacaoVegetativa.pdf>.

MARIOSA, T. N. Potencial de enraizamento de Estacas Semilenhosas de Oliveira (Olea europaea L.) inoculadas com Rizobactérias. 2014. 68 f. Dissertação (Mestrado em Meio Ambiente e Recursos Hídricos) - Universidade Federal de Itajubá, Itajubá, 2014. Disponível em: <https://repositorio.unifei.edu.br/xmlui/handle/123456789/306>.

MENDES, A. D. R. LACERDA, T. H. S.; ROCHA, S. M. G.; MARTINS, E. R. Growth regulators and substrates on rooting of Varronia curassavica Jacq. Revista Brasileira de Plantas Medicinais, v. 16, n. 2, p. 262-270, 2014. Disponível em: <http://dx.doi.org/10.1590/S1516-05722014000200015>. doi: 10.1590/S151605722014000200015

MAIA, J. D. G.; CAMARGO, U. A. Sistema de Produção de Uvas Rústicas para Processamento em Regiões Tropicais do Brasil. Sistema de Produção - 9, Versão Eletrônica, $2005 . \quad$ Disponível em: <http://sistemasdeproducao.cnptia.embrapa.br/FontesHTML/Uva/UvasRusticas ParaProcessamento/cultivares>.

NORBERTO, P. M.; CHALFUN, N. N. J.; PASQUAL, M.; VEIGA, R. D.; PEREIRA, G. E.; MOTA, J. H. Efeito da época de estaquia e do AIB no enraizamento de estacas de figueira (Ficus carica L.). Ciência e Agrotecnologia, Lavras, v. 25, n. 3, p. 533- 
541 ,

2001.

Disponível

em:

https://www.researchgate.net/publication/237805920_Efeito da época de estaquia e do AIB no enraizamento de estacas de Figueira -FicuscaricaL>.

OLIVEIRA, A. P.; NIENOW, A. A.; CALVETE, E. O. Capacidade de enraizamento de estacas semilenhosas e lenhosas de cultivares de pessegueiro tratadas com AIB. Revista Brasileira de Fruticultura, Jaboticabal, v. 25, n. 2, p. 282-285, 2003. Disponível em: < http://dx.doi.org/10.1590/S0100-29452003000200025>. doi: 10.1590/S0100-29452003000200025

OLIVEIRA, T. P. F. BARROSO, D. G. LAMÔNICA, K. R. CARVALHO, V. S. OLIVEIRA, M. A. Efeito do ácido indol-3-butírico (aib) no enraizamento de miniestacas de ipê-roxo (Handroanthus heptaphyllus MATTOS). Ciência Florestal. v. 25, n. 4, p. 1043-1051, 2015. Disponível em: <http://dx.doi.org/10.5902/1980509820666>. doi: 10.5902/1980509820666

PETRI, J. L.; HAWERROTH, F. J. LEITE, G. B.; SEZERINO, A. A.; COUTO, M. Reguladores de crescimento, importância, perspectivas e utilização. Embrapa Uva e Vinho - Livro científico (ALICE). Florianópolis, 2016. Disponível em: $<$ https://www.embrapa.br/web/mobile/publicacoes/-/publicacao/1047582/reguladoresde-crescimento-importancia-perspectivas-e-utilizacao>.

RAUT, J. S.; KARUPPAYIL, S. M. A. A. status review on the medicinal properties of essential oils. Industrial Crops and Products, v. 62, p. 250-264, 2014. Disponível em: <https://doi.org/10.1016/j.indcrop.2014.05.055>. doi: 10.1016/j.indcrop.2014.05.055

ROSA, G. G. ZANANDREA, I. MAYER, N. A. BIANCHI, V. J. Propagação de portaenxerto de Prunus spp. por estaquia: efeito do genótipo, do estádio de desenvolvimento do ramo e tipo de estaca. Revista Ceres, v. 64, n.1, p. 90-097, 2017. Disponível em: <http://dx.doi.org/10.1590/0034-737x201764010013>. doi: 10.1590/0034-737x201764010013

SAINI, S. SHARMA, I. KAUR, N. PATI, P. K. Auxin: a master regulator in plant root development. Plant Cell Reports. Berlin, v. 32, n. 6, p. 741-757, 2013. Disponível em: < http://dx.doi.org/10.1007/s00299-013-1430-5>. doi:10.1007/s00299-013-14305. 
SANTOS, J. P. DAVIDE, A. C. TEIXEIRA, L. A. F. MELO, A. J. S. MELO, L. A. Enraizamento de estacas lenhosas de espécies florestais. Cerne. v. 17, n. 3, p. 293301, 2011. Disponível em: <http://dx.doi.org/10.1590/S0104-77602011000300002>. doi: 10.1590/S0104-77602011000300002

SANTOS, V. M. C. S.; SCHNEIDER, T. R.; BIZZO, H. R. DESCHAMPS, C. Alternativas de propagação na produção de óleo essencial de Mentha canadensis $L$. no Litoral Norte Catarinense. Revista Brasileira de Plantas medicinais, v.14, n.1, p. 97-102. 2012. Disponível em: <http://dx.doi.org/10.1590/S151605722012000100014>. doi: 10.1590/S1516-05722012000100014

SOUZA, C. S. S. CORREAA, L. S. Efeito do tempo de imersão em IBA no enraizamento de estacas de figueira, sob nebulização intermitente. Revista Visão Universitária. v. 22, p. 45-48, 2008. Disponível em: < http://dx.doi.org/10.4025>. doi: 10.4025 .

TAIZ, L.; ZEIGER, E. Fisiologia vegetal. 5. ed. Porto Alegre: Artmed, 2013. 954 p.

TARFURT-GARCIA, G.; MUNÕZ-AZEVEDO, A.; CALVO, A. M.; JIMENÉZ, L. F.; DELGADO, W. A. Componentes volátiles de Eriope crassipes, Hyptis conferta, $\mathrm{H}$. dilatata, $H$. brachiata, $H$. suaveolens y $H$. mutabilis (Lamiaceae). Boletin Latinoamericano y del Caribe de Plantas Medicinales y Aromaticas, v.13, n.3, p. 254-259, 2014. Disponível em: <http://www.blacpma.usach.cl/revistanumero/componentes-volatiles-de-eriope-crassipes-hyptis-conferta-h-dilatata-hbrachiata-h>.

TIBERTI, A. S.; BIANCHINI, F. G.; PIO, R.; CURI, P. N; MOURA, P. H. A.; TADEU, M. H. Armazenamento a frio e aplicação de reguladores vegetais no enraizamento de estacas radiculares e caulinares de framboeseira. Ciência Rural, v. 45, n. 8, p. 1445-1450, 2015.2 Disponível em: <http://www.redalyc.org/pdf/331/33142184016.pdf>.

TOSTA, M. S. OLIVEIRA, C. V. F. FREITAS, R. M. O. PORTO, V. C. N. NOGUEIRA, N. W. TOSTA, P. A. F. Ácido indolbutírico na propagação vegetativa de cajaraneira (Spondias sp.). Semina: Ciências Agrárias, Londrina, v. 33, suplemento 1, p. $2727-$ 2740, 2012. Disponível em: < http://dx.doi.org/10.5433/1679-0359> doi: 10.5433/1679-0359. 
VERNIER, R. M. CARDOSO, S. B. Influência do ácido indolbutírico no enraizamento de estacas em espécies frutíferas e ornamentais. Revista Eletrônica de Educação e Ciência, Avaré. v. 3. n. 2. p. 11-16, 2013. Disponivel em: $<$ http://fira.edu.br/revista/vol3_num2_pag11.pdf>. 